\title{
Optical and Electrical Properties of Copper Doped Cadmium Oxy-Sulphide Quaternary Thin Films by MOCVD Technique
}

\author{
Sabur Abiodun Ayinde ${ }^{1,2}$, Adetokunbo T. Famojuro ${ }^{3}$, Oladepo Fasakin ${ }^{1}$, Bolutife Olofinjana ${ }^{1}$, \\ Adetayo Victor Adedeji ${ }^{4}$, Moses Sesan Eluyemi ${ }^{1}$, Marcus Adebola Eleruja ${ }^{1}$, \\ Ezekiel Oladele Bolarinwa Ajayi ${ }^{1}$
}

${ }^{1}$ Department of Physics and Engineering Physics, Obafemi Awolowo University, Ile-Ife, Nigeria

${ }^{2}$ Department of Physics/Electronics, Federal Polytechnic, Ede, Nigeria

${ }^{3}$ Department of Chemistry, Obafemi Awolowo University, Ile-Ife, Nigeria

${ }^{4}$ Department of Chemistry and Physics, Elizabeth City State University, Elizabeth City, NC, USA

Email address:

saburayinde@yahoo.com (S. A. Ayinde)

\section{To cite this article:}

Sabur Abiodun Ayinde, Adetokunbo T. Famojuro, Oladepo Fasakin, Bolutife Olofinjana, Adetayo Victor Adedeji, Moses Sesan Eluyemi, Marcus Adebola Eleruja, Ezekiel Oladele Bolarinwa Ajayi. Optical and Electrical Properties of Copper Doped Cadmium Oxy-Sulphide Quaternary Thin Films by MOCVD Technique. International Journal of Materials Science and Applications.

Vol. 6, No. 4, 2017, pp. 223-229. doi: 10.11648/j.ijmsa.20170604.19

Received: January 4, 2016; Accepted: June 28, 2017; Published: July 26, 2017

\begin{abstract}
A prepared single solid source precursor was used for the deposition of copper doped oxy-sulphide thin films on glass substrate by MOCVD technique. This was achieved by the pyrolysis of the prepared precursors at $420^{\circ} \mathrm{C}$ with a flow rate of $2.5 \mathrm{dm}^{3} / \mathrm{min}$ for 2 hours. The deposited films were characterized using Rutherford Backscattering Spectroscopy (RBS), Scanning Electron Microscopy (SEM), UV-visible spectrophotometry and four point probe method. RBS analysis showed that the expected elements are present while the thickness was estimated to be $889 \mathrm{~nm}$. The SEM images of the deposited film showed a fine structure with densely packed grains of uniform grain size of about $80 \mathrm{~nm}$, well distributed throughout the entire substrate which is polycrystalline in nature. The film revealed an average transmittance of $80 \%$ in the visible region with a direct bandgap of $2.41 \mathrm{eV}$. The absorbance of the film was observed to be low in the visible and near-infrared regions, and high in UV region. The values of $1.17 \times 10^{9} \Omega / \square$ and $10.40 \Omega \mathrm{cm}$ were obtained as the sheet resistance and resistivity of the film respectively. The deposited quaternary thin film is found to be a promising candidate as window layer and absorber layer for cost effective photovoltaics.
\end{abstract}

Keywords: Copper Cadmium Oxy-Sulphide, Precursor, Metal Organic Chemical Vapor Deposition (MOCVD), Thin Film, Characterization

\section{Introduction}

Cadmium Sulphide (CdS) belongs to group II-IV semiconductor with wide band gap energy $(2.42 \mathrm{eV})$ [1] covering the visible spectrum range. It is a direct band gap material and one of the most useful semiconductor materials with its wide range of applications in semiconductor devices such as fabrication of solar cells as optical windows [2], piezo-electronic and optoelectronic [3] devices such as thin film optical integrated circuits. CdS thin films are also useful in electronic devices such as field effect transistor [2], light emitting diodes [4]. In the case of thin film solar cells, it has been reported that efficient thin film solar cells are obtained using $\mathrm{CdS}$ as an n-partner. The highest efficiency so far reported for CdS thin film solar cells is $16.5 \%$ [11].

Meanwhile, chalcogenides copper sulphide $(\mathrm{CuS})$ have found wide range application in the fabrication of microelectronic devices, optical filters as well as in low 
temperature gas sensor applications. Moreover, ternary copper chalcogenides like copper indium diselenide, and copper indium gallium selenides, in recent times, are now widely used in the fabrication of solar photovoltaic cells

The CdS has been prepared by spray pyrolysis $[5,6]$, vacuum deposition [7], molecular beam epitaxy, solution growth [8], chemical bath deposition [9] and metal organic chemical vapour deposition (MOCVD) [10]. MOCVD also known as Organo Metallic Vapour Pressure Epitaxy (OMVPE) is a technique that is attractive because it makes use of a single solid precursor prepared cheaply from appropriate reagents and can also be modified for quality and better reproducibility of the film with desired properties. Metal organic reactions occur at lower temperature than reduction reactions and do not attack the substrates chemically. MOCVD with thermal energy source is used for growing epitaxial films for many optoelectronic devices of compound semiconductors for solar cells, LEDs, photocathodes, and quantum wells. The use of single solid source precursor reduces the number of process parameters that controls the properties of the deposited film. Eleruja et al., (1998) [13] used the procedure involving single solid source precursor to deposit $Z n_{x} C d_{1-x} S$ thin films.

The aim of this work is to study the morphological, optical and electrical properties of copper doped cadmium oxy-sulphide thin films prepared by MOCVD technique, such that it could be used as an absorber layer for a typical solar cell.

\section{Experimental Procedure}

Single solid source precursor for the quaternary thin films of copper doped cadmium oxy-sulphide was prepared by the modification of the method reported by Eleruja et al., 1998 [13]. This method has also been extended to cover oxysulphide in the past $[14,15]$. Ammonium morpholinodithiocarbamate which is the intermediate compound was prepared as reported by Ajayi et al. 1994. 8.6 g of ammonium morpholino-dithiocarbamate was dissolved in ethyl-ether and de-ionized water. $19.2 \mathrm{~g}$ of cadmium acetate was dissolved in acetone and de-ionized water in a separate beaker. $0.8 \mathrm{~g}$ of copper acetate was also dissolved in methanol and de-ionized water. The cadmium acetate solution was gradually added to the ammonium morpholino-dithiocarbamate solution with vigorous stirring after which the copper acetate solution was gradually added. The product was heated for some time and later precipitated. The precipitate was filtered and dried in an oven which was maintained at $70^{\circ} \mathrm{C}$.

The precursor was pyrolysed on sodalime glass substrate using previously reported MOCVD technique [13, 15, and 16]. The dried precursor was grounded to fine powder and poured into a receptacle (Figure 1) which was easily transported by nitrogen gas into the reaction chamber where the film deposition takes place. The pyrolysis was carried out at a deposition temperature of $420^{\circ} \mathrm{C}$ with a flow rate of 2.5 $\mathrm{dm}^{3} /$ minutes for 2 hours. The deposited copper doped cadmium oxy-sulphide thin films were then annealed at $500^{\circ} \mathrm{C}$ for 2 hours to improve crystallinity and morphology.

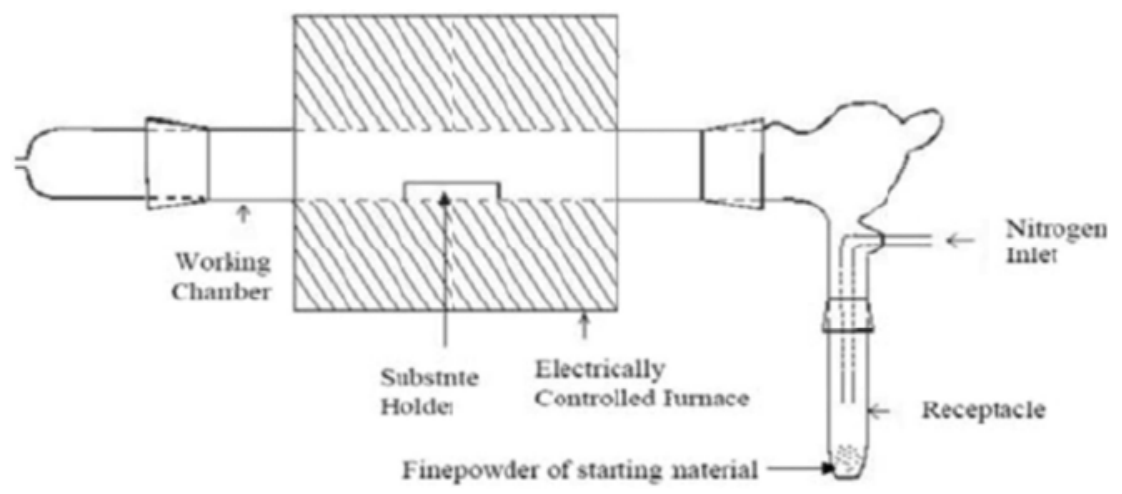

Figure 1. Appratus for MOCVD Technique.

Rutherford backscattering spectroscopy (RBS) was used to determine the elemental composition, stoichiometry and thickness of the films. This was done using a $7 \mathrm{MV}$ Tandem accelerator with $\mathrm{He}^{+}$of energy $2.2 \mathrm{MeV}$ as incident particle. The spectrum was obtained under IBM geometry (scattering configuration where the incident beam, surface normal and detected beam, are all coplanar). The detector solid angle was $0.833 \mathrm{msr}$ with resolution of $12 \mathrm{keV}$. The beam current was $3.8 \mathrm{nA}$ with integrated beam dose of $10.0 \mu \mathrm{C}$.

A Jeol 6700F Ultra High Resolution Scanning Electron Microscope was used to study the morphology of the films. This was achieved with a working distance ( $Z$ height) of 15 using $\mathrm{Z}$ height control, operating at an accelerating voltage of $2 \mathrm{kV}$, and a current of $12 \mu \mathrm{A}$. Electron beam is swept across the area of inspection, and a positively biased grid or detector collects an attracted dislodged electrons and translate them into signals. These signals are then amplified, analyzed, and translated into images of the topography being inspected. Finally, the image is shown on a cathode ray tube (CRT).

The optical behavior of the films was studied by investigating the optical absorbance of the thin films using PYE UNICAM UV Visible spectrophotometer. All measurements were done at room temperature with blank sodalime glass in the reference beam. Standardization was done by first replacing the film with the sodalime glass in the sample position thus having a plain against a plain substrate.

The electrical characterization of the films was done using four point probe technique. The four point collinear probe 
configuration was used. Silver paste was deposited at the four points for ohmic contact. The deposited silver paste was cured for 24 hours at $50^{\circ} \mathrm{C}$. The current and voltage measurements were done using Keithley 2400 source meter with Rolls and Keener probes. The two outer probes sourced the current while the two inner probes sensed the resulting voltage drop across the film.

\section{Result and Discussion}

\subsection{Rutherford Backscattering Spectroscopy (RBS) Analysis}

The composition, stoichiometry and thickness of the deposited film were determined using RBS. The RBS spectrum of the deposited film is shown in Figure 2. The spectrum revealed the presence of $\mathrm{Cu}, \mathrm{Cd}, \mathrm{S}$, and $\mathrm{O}$ as the constituent elements of the film. The stoichiometric ratio of these elements as analyzed by the RBS are $\mathrm{Cu}=4.20 \%, \mathrm{Cd}=$
$10.77 \%, \mathrm{~S}=33.74 \%$, and $\mathrm{O}=51.27 \%$. This shows that the decomposition of the single solid precursor in nitrogen gas medium produced copper doped cadmium oxy-sulphide thin films. The large amount of oxygen contained in the film can be attributed to the abundance of oxygen in the starting material [15], and in addition to some elements migrating from the glass slide to the film at the annealed $500^{\circ} \mathrm{C}$ temperature. The film thickness was calculated using the following relations;

$$
\text { thickness }(\mathrm{cm})=\frac{\text { atoms } / \mathrm{cm}^{2}}{\text { atomic density }\left(\text { atoms } / \mathrm{cm}^{3}\right.}
$$

$$
\text { atomic density }=\frac{\rho N_{a}}{m}
$$

where $\rho$ is density number, $N_{a}$ is Avogadro's number$6.022 \times 10^{23}$ atoms $/$ moles, and $m$ is gram atomic weight.

The thickness obtained from RBS analysis was $1925.76 \times$ $10^{15}$ atoms $/ \mathrm{cm}^{2}$, which was estimated to be $889 \mathrm{~nm}$.

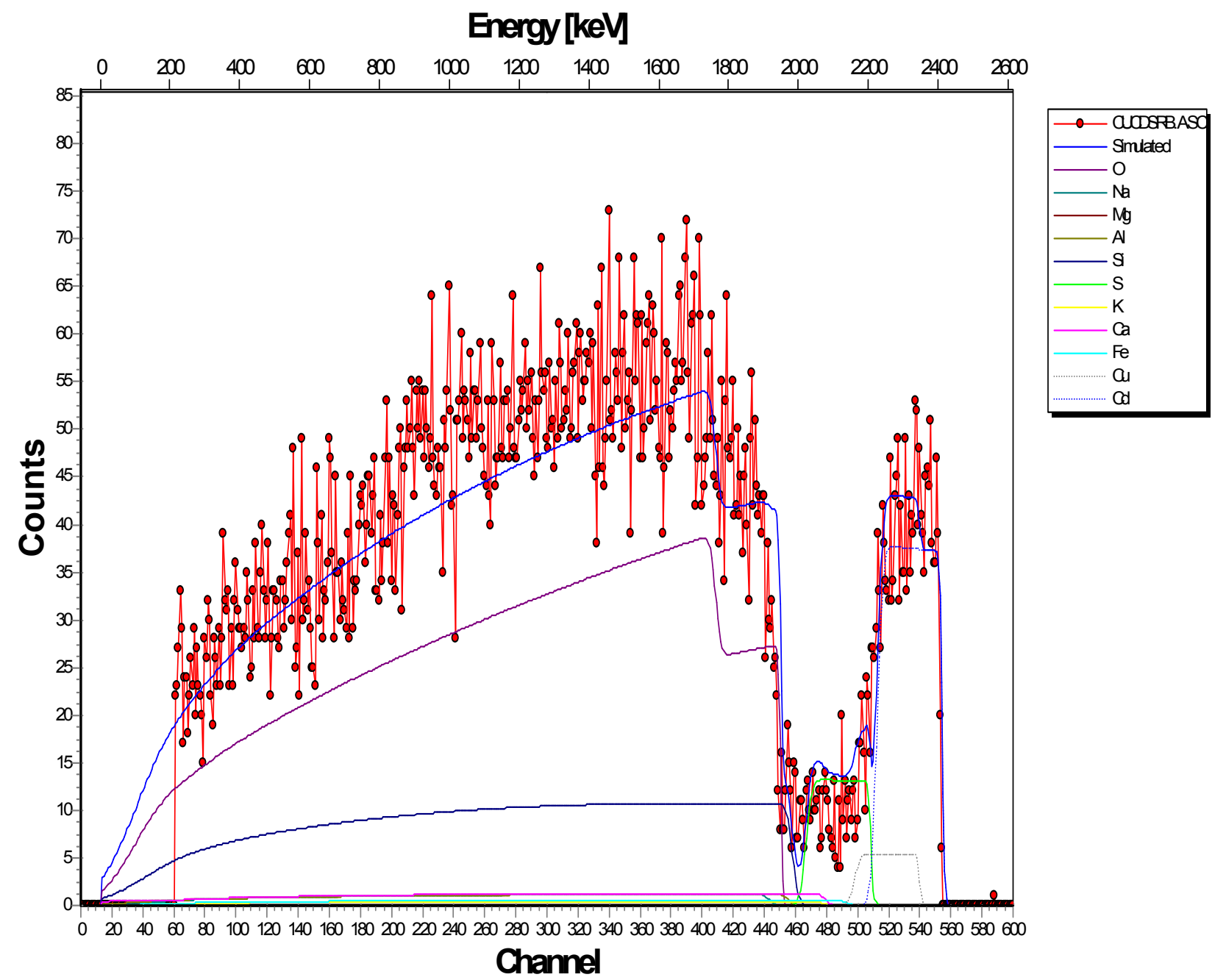

Figure 2. RBS Spectrum of CdSO:Cu Thin Film.

\subsection{Morphological Studies}

The Scanning electron micrograph of the deposited copper doped cadmium oxy-sulphide thin film is shown in Figure 3.
The film was annealed at $500^{\circ} \mathrm{C}$ for an hour. The micrograph revealed that the film is polycrystalline and less-porous in nature. This result is in accordance with the report of Shah et al., 2012 [17]. The annealed film gave a fine structure with densely 
packed grains of uniform grain size, well distributed throughout the entire substrate. This suggests that the deposited film adhere well to the substrate without any crack [18]. The slight nonuniformity observed in the film at higher magnifications (Figure $3 \mathrm{~b}$ and $3 \mathrm{c}$ ) may suggest that there was non-uniform nucleation at some point in the substrate surface. This agrees with the work of Agarwal et al., 2014 [19] on CdS thin film. From the SEM micrograph the grain size of the thin film was estimated to be 80 $\mathrm{nm}$. The grain size and configuration of the pyrolytic deposited quaternary thin films are dependent on many parameters such as deposition time, temperature of substrate, nature of substrate, etc. [20]. The film has a desirable stability which can be employed in photovoltaic applications.
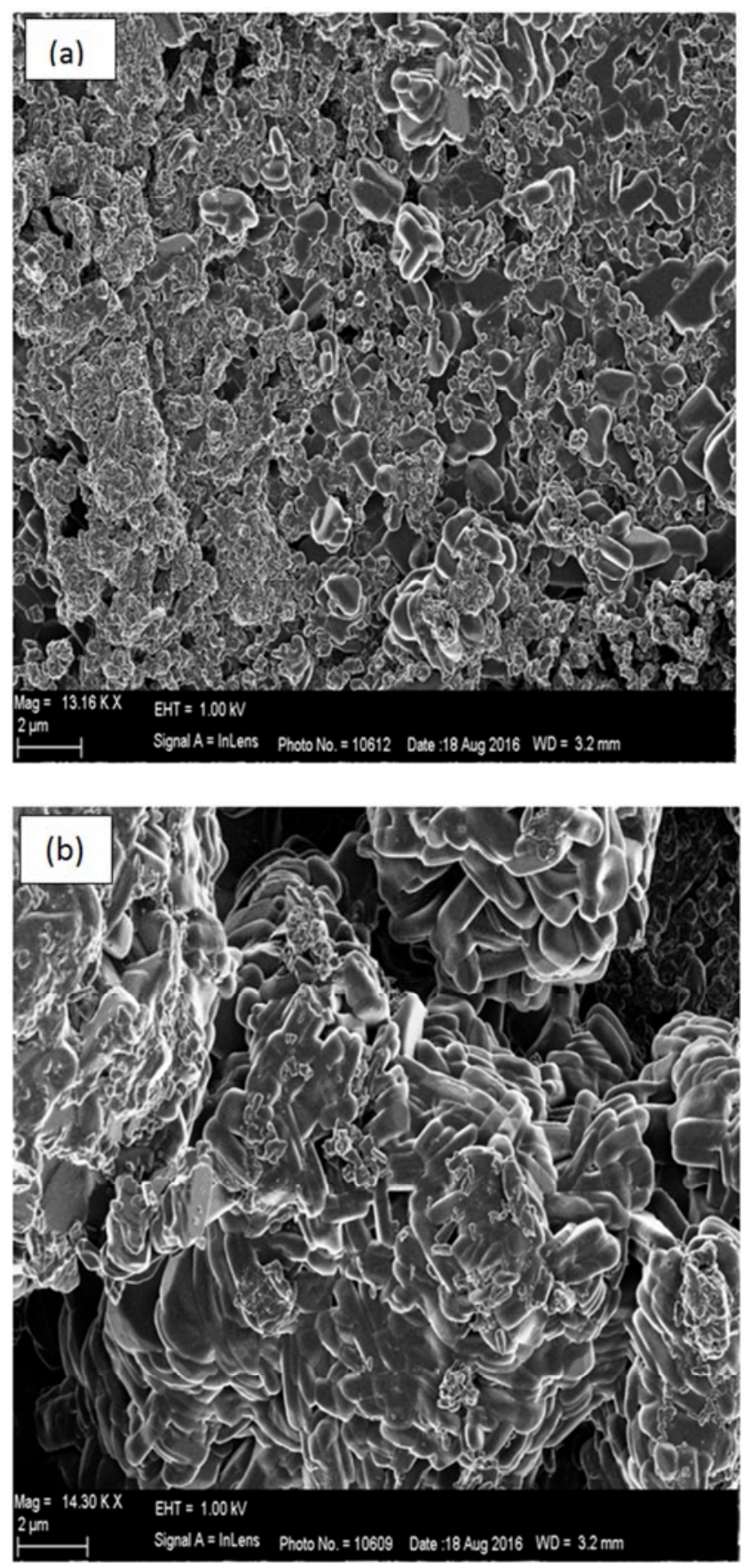

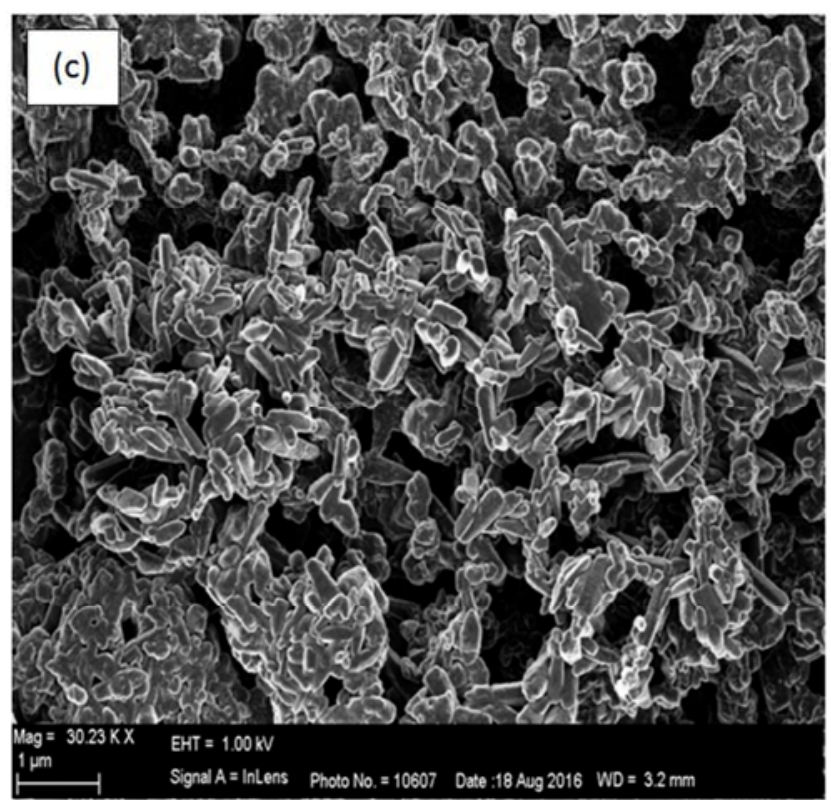

Figure 3. SEM micrograph of CdSO: Cu thin film annealed at $500^{\circ} \mathrm{C}$.

\subsection{Optical Characterization}

The UV-visible spectrum for optical characterization of $\mathrm{CdSO}: \mathrm{Cu}$ film was obtained using visible spectrophotometer in the range of 200-1100 nm. The absorbance $A$, transmittance $T$, absorption coefficient $\alpha$, and energy $E$ were calculated using the appropriate equations;

$$
A=\log 1 / T
$$

Where $A$ is the absorbance and $T$ is the transmittance. For Lambertian law of absorption, we have;

$$
I=I_{0} \exp \left(-\alpha t_{p}\right)
$$

and

$$
T=I^{I} I_{0}=\exp \left(-\alpha t_{p}\right)
$$

where $t_{p}$ is the thickness of the film determined by the RBS, $\alpha$ is absorption coefficient, $I$ is the intensity of transmitted light and $I_{0}$ is the intensity of incident light. Thus, equation 3 becomes;

$$
\begin{gathered}
\frac{1}{T}=\exp \left(\alpha t_{p}\right) \\
\text { Hence, } \alpha=\frac{1}{t_{p}} \ln \frac{1}{T}
\end{gathered}
$$

The energy $\mathrm{E}(\mathrm{eV})$ was calculated using the relation;

$$
E=\frac{h c}{\lambda}
$$

Where, $h$ is planck's constant, $c$ is velocity of light, and $\lambda$ is wavelength of the incident beam in $\mathrm{nm}$.

Figure 4 shows the optical transmission spectrum of the deposited $\mathrm{Cu}$ doped $\mathrm{CdSO}$ thin film. The transmittance is high in wavelength range $345-800 \mathrm{~nm}$ and an average transmittance value of over $80 \%$ was recorded. Figure 5 
shows the reflectance spectrum of the films. The reflectance recorded was relatively low, about $2.0 \%$ to $6.5 \%$ in the visible region. This is a good result compared to the transmittance of copper doping $\mathrm{CdS}$ thin films varying from $30 \%$ to $40 \%$ in visible region by Shah et al., 2012 [17].

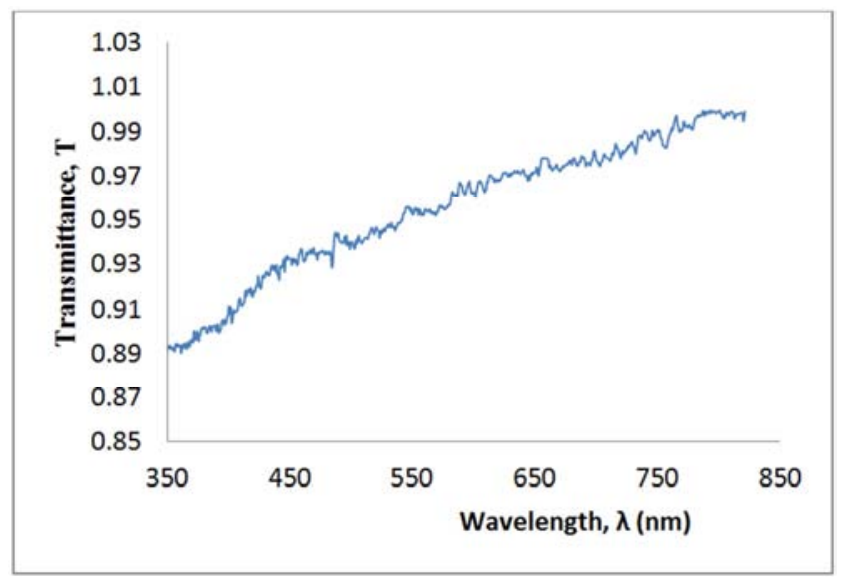

Figure 4. Variation of transmittance (T) of $\mathrm{CdSO}: \mathrm{Cu}$ thin film with wavelength.

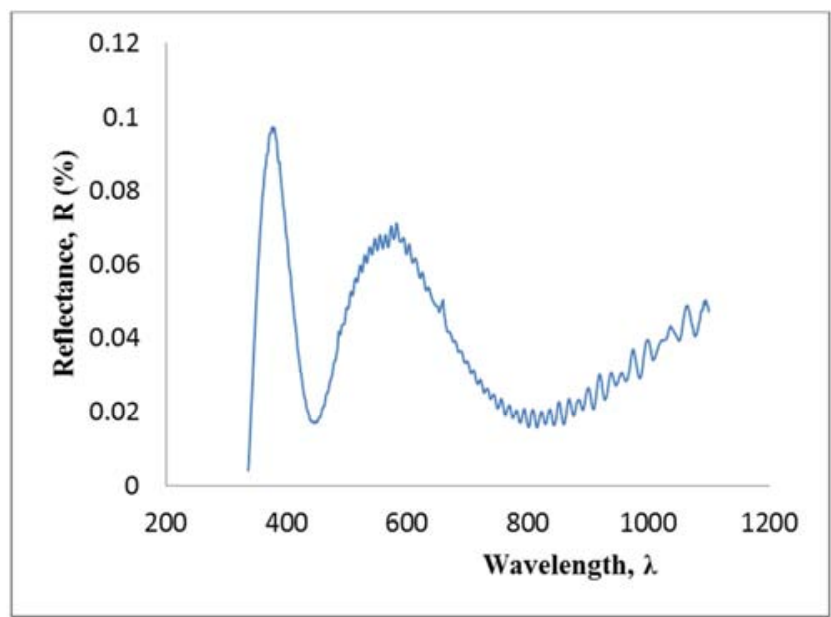

Figure 5. Variation of reflectance ( $R$ ) of CdSO:Cu thin film with wavelength.

Figure 6 shows the plot of absorbance versus wavelength plot. The absorbance of CdSO:Cu film was observed to be low in the VIS/NIR regions and high in UV region. This is in agreement with the report of Awodugba et al., 2012 [21] on $\mathrm{CdS}: \mathrm{Cu}$. It was also revealed that the maximum absorbance of $\mathrm{CdSO}: \mathrm{Cu}$ was obtained at about $350 \mathrm{~nm}$. Similar behavior was also observed in the case of on $\mathrm{CdS}: \mathrm{Cu}$ thin films by Kumar et al., 2015 [22], high transmittance $(\sim 60-90 \%)$ and low absorbance near infrared region $(\sim 500-1000 \mathrm{~nm})$ obtained by Ganesh et al., 2013 [23], thus making the film suitable for optoelectronic devices for instance window layer on solar cells [24].

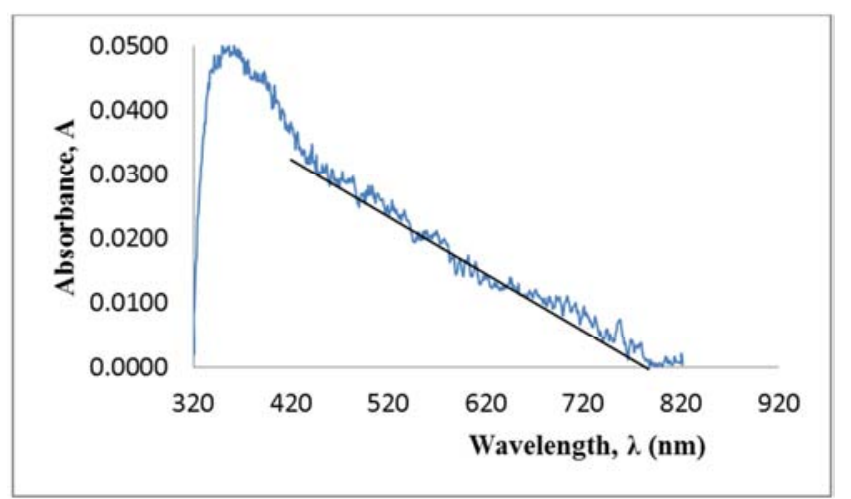

Figure 6. Variation of Absorbance (A) of CdSO:Cu thin film with wavelength.

The energy gap of the thin film can be calculated by equation (7) [13];

$$
\alpha h v=A\left(h v-E_{g}\right)^{N / 2}
$$

where $A$ is constant, $h v$ is the photon energy, $E_{g}$ is the energy gap and $N$ depends on the nature of transition. $N$ is considered to be 1 since the material showed a direct transition (one absorption edge).

After extrapolating the linear segment of the curve to $(\alpha h v)^{2}=0$, with $4 \% \mathrm{Cu}$ doping concentration in the film, Figure 7 showed that the optical bandgap of the film is 2.40 $\mathrm{eV}$. This result agrees with several works on $\mathrm{CdS}: \mathrm{Cu}$, for instance Shah et al., 2012 reported a bandgap of $2.41 \mathrm{eV}$, minutely reduced from $2.42 \mathrm{eV}$ for low $\mathrm{Cu}$ concentration in $\mathrm{CdS}: \mathrm{Cu}$. Different authors have reported various different band gap value for copper doped CdS thin films with various concentration of copper. Tariq et al., 2013 [24] reported that the bandgap decreases from $2.41 \mathrm{eV}$ to $2.451 \mathrm{eV}$ for $\mathrm{CdS}: \mathrm{Cu}$ at $2 \%$ of $\mathrm{Cu}$. Ali et al., 2006 [25] also reported a bandgap of $2.41 \mathrm{eV}$ for low $\mathrm{Cu}$ concentration in $\mathrm{CdS}: \mathrm{Cu}$. Najiba and Ameer 2012 [26], reported a bandgap range of 2.4-2.413 eV for copper doped CdS films. All these reports were in accordance with our result as low dopant $\mathrm{Cu}$ concentration in $\mathrm{CdS}$ resulted in slight reduction in energy bandgap.

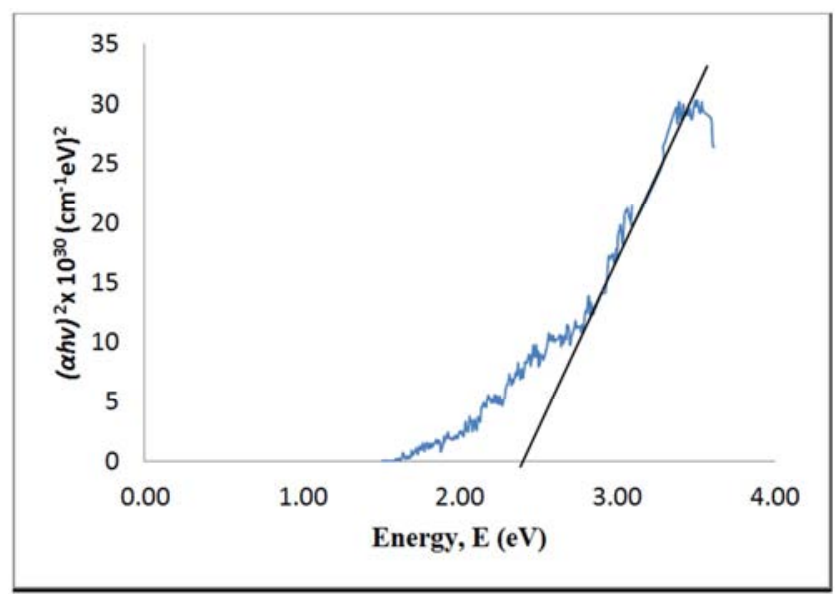

Figure 7. $\alpha h v^{2}$ versus Energy for CdSO:Cu thin film. 


\subsection{Electrical Characterization}

The electrical analysis of $\mathrm{CdSO}: \mathrm{Cu}$ film was carried out using $\mathrm{v}$ an der Pauw four point probes method. The average current and the corresponding average voltage were determined from a plot of current versus voltage (Figure 8 ) to be $1.94 \times 10^{-10} A$ and $5.01 \times 10^{-2} V$ respectively.

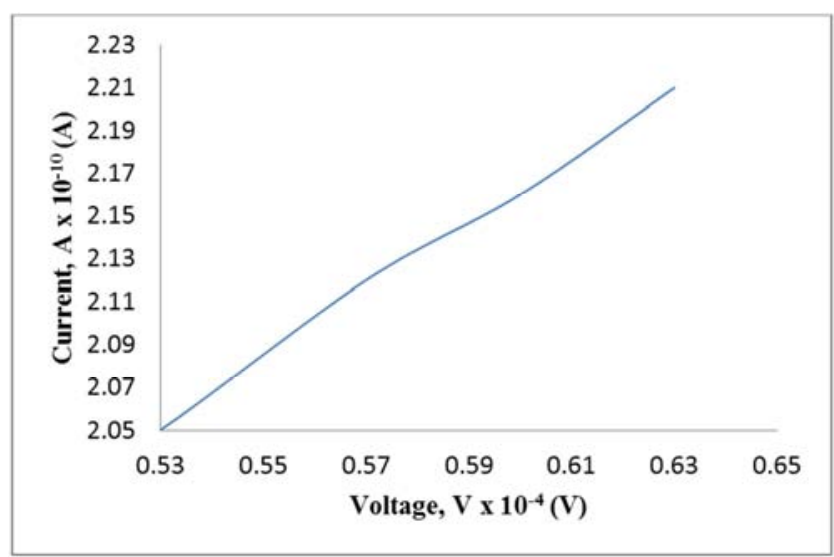

Figure 8. I-V characteristics of CdSO:Cu thin film.

The sheet resistance was determined using the relation;

$$
R_{s}=k \frac{V}{I}
$$

Where $V$ and $I$ are the voltage and current respectively, $k$ is a constant that depends on the configuration and the spacing of the contacts. In this case:

$$
k=\frac{\pi}{\operatorname{In} 2}=4.5324
$$

The resistivity of the film was calculated in terms of average sheet resistance $(\Omega / \square)$ using

$$
\rho=R_{s} t_{p}
$$

The thickness $t_{p}=889 \mathrm{~nm}$ was obtained from the RBS analysis. Using Eq.10, the sheet resistance was calculated to be $1.17 \times 10^{9} \Omega / \square$. The resistivity of the film was $10.40 \Omega \mathrm{cm}$ as calculated using Eq. 12, which agrees with the value $10 \Omega \mathrm{cm}$ reported by Tariq et al., 2013 [24] as the electrical measurements showed that the conductivity of $\mathrm{CdS}$ films doped with copper was dependent on doping concentration. The low resistivity or high conductivity of the $\mathrm{CdSO}: \mathrm{Cu}$ film is as a result of conversion from n-type to $\mathrm{p}$ type for a high concentration of $\mathrm{Cu}$ as a dopant. This was achieved when the copper ions replaced $\mathrm{Cd}^{+2}$ in substitutional sites, which plays the role of acceptor-type impurity.

\section{Conclusion}

Attempt has been made in this study to deposit copper doped cadmium oxy-sulphide thin films from a single solid source precursor using MOCVD method. The deposited films were also characterized by RBS, SEM, UV-visible spectrophotometry and van der Paw four point probe method.
Based on the result of this work the following conclusion can be made

RBS analysis confirmed the expected elements with the stoichiometry ratio of constituent elements given as $\mathrm{Cu}=$ $4.20 \%, \mathrm{Cd}=10.77 \%, \mathrm{~S}=33.74 \%$, and $\mathrm{O}=51.27 \%$. The thickness of the film was also estimated to be $889 \mathrm{~nm}$ from the RBS analysis. The SEM micrograph of the deposited film showed a fine structure with densely packed grains of uniform grain size, well distributed throughout the entire substrate which is polycrystalline in nature. The UV-visible analysis of copper doped cadmium oxy-sulphide thin films has a direct bandgap of $2.41 \mathrm{eV}$. The absorbance of the film was also observed to be low in the VIS/NIR regions and high in UV region. The sheet resistance and the resistivity of the film are $1.17 \times$ $10^{9} \Omega / \square$ and $10.40 \Omega \mathrm{cm}$ respectively as revealed from the $\mathrm{I}-\mathrm{V}$ electrical characterization.

It is believed that the synthesis of copper doped cadmium oxy-sulphide thin films from single solid source precursor provide another method for preparing copper doped cadmium oxysulphide thin film via MOCVD technique using our simple set-up. A simple and cost effective method that is well suitable for the production of copper doped cadmium oxysulphide thin films on a large scale is established. The deposited quaternary thin films could be used as window layer and absorber layer for cheap solar cells.

\section{Acknowledgements}

The authors would like to appreciate the Elizabeth City State University North Carolina USA for the optical characterization. We would also like to appreciate Prof. Obiajuwa of Centre for Energy Research and Development (CERD), Obafemi Awolowo University, Ile-Ife, Nigeria for the RBS analysis.

\section{References}

[1] N. A. Shah, W. A. Syed, M. A. Atta, M. Ajmal, A. Ali and A. Maqsood. Nanosci. Nanotechnol. Lett. 1 (2009) 62.

[2] A. V. Feitosa, M. A. Miranda, J. M. Sasaki and M. A. AraujoSilva, Braz. J. Phys.,34, 2B, (2004) 656-658.

[3] P. K. Nair, O. Gomezdaza and M. T. S. Nair, Adv. Mater. Opt. Electr., 1 (1992) 139.

[4] J. T. Hu, T. W. Odom and C. M. Lieber. Acc. Chem. Res. 32 (1999) 435.

[5] L. Isac, A. Duta and A. Kriza. Thin Solid Films, 15 (2007) 5755-5758.

[6] E. Ienei, L. Isac and A. Duta. Revue Roumaine de Chimie, 3 (2010) 161-165.

[7] A. G. Rolo, U. Gonde and M. J. M. Gomes. Thin Solid Films, 318 (1998) 108-112.

[8] J. Juza and J. Cermak. Chemical Engineering Science, 35(1), (1980) 429-436. 
[9] M. A. Barote, A. A. Yadav, T. V. Chavan and E. U. Masumdar. Digest J. Nanomaterials and Biostructures, 6 (2011) 979-990.

[10] O. B. Ajayi, O. K. Osutola, I. A. Ojo and C. Jeynes. Thin Solid Films, 248 (1994) 57-63.

[11] N. Romeo, A. Bosio and A. Romeo. Solar Energy Mater. Solar Cells (2008) 45-55.

[12] A. A. Bosak, C. Duboudieu, J. P. Sènateur, O. Y. Gorbenko and A. R. Kaul. Journal of Materials Chemistry, 12(4), (2002) 800-801.

[13] M. A. Eleruja, A. V. Adedeji, I. A. O. Ojo, A. Djebah, O. Osasona, J. B. Aladekomo and E. O. B. Ajayi. Optical Materials, 10 (1998) 257-263.

[14] A. V. Adedeji, M. A. Eleruja, I. A. O. Ojo, A. Djebah, O. Osasona, J. O. Olowolafe, J.B. Aladekomo and E. O. B. Ajayi: Opt. Mater., 2000, 14, 345.

[15] B. Olofinjana, G. O. Egharevba, M. A. Eleruja, C. Jeynes, A. V. Adedeji, O. O. Akinwunmi, B. A. Taleatu, C. U. Mordi, and E. O. B. Ajayi. Journal of Materials Science \& Technology 26, no. 6 (2010): 552-557.

[16] E. Omotoso, G. A. Adegboyega, M. A. Eleruja, B. Olofinjana, O. O. Akinwunmi, O. O. Ilori, B. A. Taleatu, E. O. B. Ajayi. Journal of Non Oxide Glasses. Vol. 5, No. 1, 2013, p. 9 - 19.

[17] N. A. Shah. Journal of Alloys and Compounds 512 (2012) 185-189.
[18] S. O. Adekoya, M. A. Eleruja, B. Olofinjana, O. O. Akinwunmi, B. A. Taleatu, and E. O. B. Ajayi. In MRS Proceedings, vol. 1432 (2012) pp. mrss12-1432. Cambridge University Press.

[19] R. Agarwal, N. K. Agarwal and R. Singh. Materials Focus, 3 (2014) $267-271$.

[20] U. Pal, R. Silva-Gonzalez, G. Mrtinez-Montes, M. GraciaJimenez, M. A. Vidal, Sh. Torres, Thin solid films 305 (1997) 345-350.

[21] A. O. Awodugba, O. Adedokun and Y. K. Sanusi. IJRRAS, 12 (2012) 3-10.

[22] V. N. Kumar, R. Suryakarthick, S. Karuppusamy, M. Gupta, Y. Hayakawa and R. Gopalakrishnan. RSC Advances, 5 (29), (2015) 23015-23021.

[23] R. Ganesh, V. Senthil Kumar, K. Panneerselvam, and M. Raja. Arch. Phys. (2013) Res. 4.

[24] A. A. Tariq and M. A. Jala. Journal of Electron Devices, 17 (2013) 1413-1427.

[25] A. Ali, N. A. Shah, A. K. S. Aqili, A. Maqsood. J. Semicond. Sci. Technol. 21 (2006) 1296.

[26] A. A. Najiba and A. H. S. Ameer. Diyala Journal for Pure Sciences, 8 (2012) No: 3. 